\title{
CYCLIC ECONOMY IN A GLOBALIZED WORLD
}

\author{
Elena A. Yakovleva ${ }^{1}$ \\ ${ }^{1}$ Department of world and national economy, Voronezh State Forestry Engineering University Named \\ after G.F. Morozov, 8 Timiryazeva Street, Voronezh 394087, Russian Federation
}

\begin{abstract}
The article is devoted to solving the problems of the development of a cyclical economy in the conditions of globalization, since the further development of society while maintaining the current growth rates of production and consumption with increasing population can lead to a global catastrophe. The traditional development model is based on intensive industrial growth and resource-intensive infrastructure. In a global cyclical economy, it is necessary to separate economic growth from resource consumption, focusing on preserving value in order to protect ecosystems and natural capital. The aim of the work is to develop tools for the transition to a cyclical economy in the context of globalization. The research methodology is based on an analysis of international and national legislation, scientific publications and ongoing projects for building elements of a cyclical economy. To model the development of cyclical development in the context of globalization, economic opportunities are identified based on specific indicators and identified barriers for which solutions and policy options are developed. For the practical implementation of the ideas of a cyclical economy, government measures are needed to overcome institutional, economic and political barriers. The transition to a cyclical economy leads to an increase in transaction costs, uncertainty, opportunistic behavior. The concept of a cyclical economy is global in nature and represents a systemic shift that shapes long-term sustainability, creates economic opportunities and provides environmental and social benefits.
\end{abstract}

\section{Introduction}

Recently, interest in a closed-loop economy has grown. The amount of natural resources is limited and the problem of environmental pollution by industrial companies is quite acute.

In the closed-loop economic model, the materials used are recycled or released into the biosphere without a harmful effect. In this case, waste is converted into useful resources. In a cyclical economy, waste is not disposed of, but sent to recycling, where it takes the form of resources for the further production of goods.

A cyclical economy is characterized as a regenerative economy with the aim of preserving the greatest possible value of products, parts and materials. This means that a system must be created that ensures a long service life, optimal reuse, recovery and processing of products and materials [1,2]. The concept of a cyclical economy is comprehensive and applicable to large and small enterprises, organizations and individuals, globally and locally. It represents a systemic shift that creates long-term sustainability, 
creates economic opportunities and provides environmental and social benefits.

In a cyclical economy, material cycles are closed, following the example of natural ecosystems, so toxic substances are removed. There is no waste since all residual flows are valuable as a resource. In addition, the products are returned after use for repair and restoration with the aim of reusing the products a second, third or fourth time, and the residual flows are separated in a biological and technical cycle [3]. Institutions and the state play a decisive role in providing the conditions for the development of a cyclical economy. They determine the direction and are the driving force behind innovation and investment [4].

A cyclical economy requires systemic thinking. All participants (enterprises, people, organisms) are part of a network in which the actions of one subject affect other participants [3]. In a cyclical economy, this is taken into account in decision-making processes by including both short-term and long-term consequences of the decision, taking into account the influence of the entire value chain and the organization of a more stable system at any scale.

In a cyclical economy, it is necessary to separate economic growth from resource consumption, focusing on maintaining value in order to protect ecosystems and natural capital. Most scientists describe a cyclical economy, referring to 3R (Reduce, Reuse, Recycle): reducing needs, reusing product details and recycling [5]. In many definitions, systemic change is seen as a fundamental part of achieving a cyclical economy.

The concept of a cyclical economy is actively promoted in the countries of Europe and Asia, legislation is being revised, conferences are held, and research results are published [6-13]. Current government policies and legislation are based on the realities of a linear economy. Therefore, they can impede the transition to a cyclical economy, both internationally and nationally $[7,8]$.

\section{Methods and Materials}

The transition to a cyclical model in the global economy has the following advantages: reduction of negative environmental impact due to reduced use of resources in production; reduction in production costs due to a decrease in the amount of primary resources used; the emergence of new markets, which means the creation of new jobs and an increase in the general level of well-being (Vanessa Prieto-Sandoval, Carmen Jaca, Marta Ormazabal, 2018) $[14,15,16]$. With a production cycle, according to the most conservative estimates, the world economy will be able to receive $\$ 1$ trillion annually by 2025 , and also create about 100 thousand new jobs in the next decade, saving \$500 million in materials and preventing the appearance of 100 million tons waste [17]. According to the new plan of the European Commission (2018), household waste disposal should be $55 \%$ by $2025,60 \%$ by 2030 , and $65 \%$ by 2035 [18]. By 2030, $70 \%$ of the packaging should be recycled. Methods should be developed for calculating recycling rates for all EU countries, measures to facilitate the reuse and stimulation of industrial symbiosis - the transformation of a byproduct of one industry into the raw materials of another industry, economic incentives for manufacturers to market organic products and support recovery and recycling schemes (e.g. for packaging, batteries, electrical and electronic equipment, vehicles).

Based on the analysis, we can identify the reasons why the cyclic model will be used in the global economy.

1. Political reasons: international and national legislation prescribes regulatory standards in the field of environment, protection and rational use of natural resources. Accordingly, international economic development strategies are being formed, for example, the European Economic Development Strategy "Europe 2020”. 
2. Economic reasons: reducing the consumption of resources helps to save money, as well as get additional profit from sales of by-products. Globally, cash exemption and new cash flows open up new development opportunities.

3. Social reasons: to increase the social responsibility of the company, various events are held. The lack of resources is associated with new models of organization of production and friction.

4. Technological reasons: thanks to the development of technology, it became possible to use the latest equipment and implement the processes that are necessary for the application of closed-loop economy models.

5. Environmental reasons: it is necessary to be more careful with the environment and minimize technogenic loads.

In a circular economy, materials do not become waste. Instead, they spread within and between different supply chains and are often transformed. There are quite serious barriers to the introduction of closed-loop economy models in the global economy: institutional, economic, legal, technological, psychological (Figure 1).

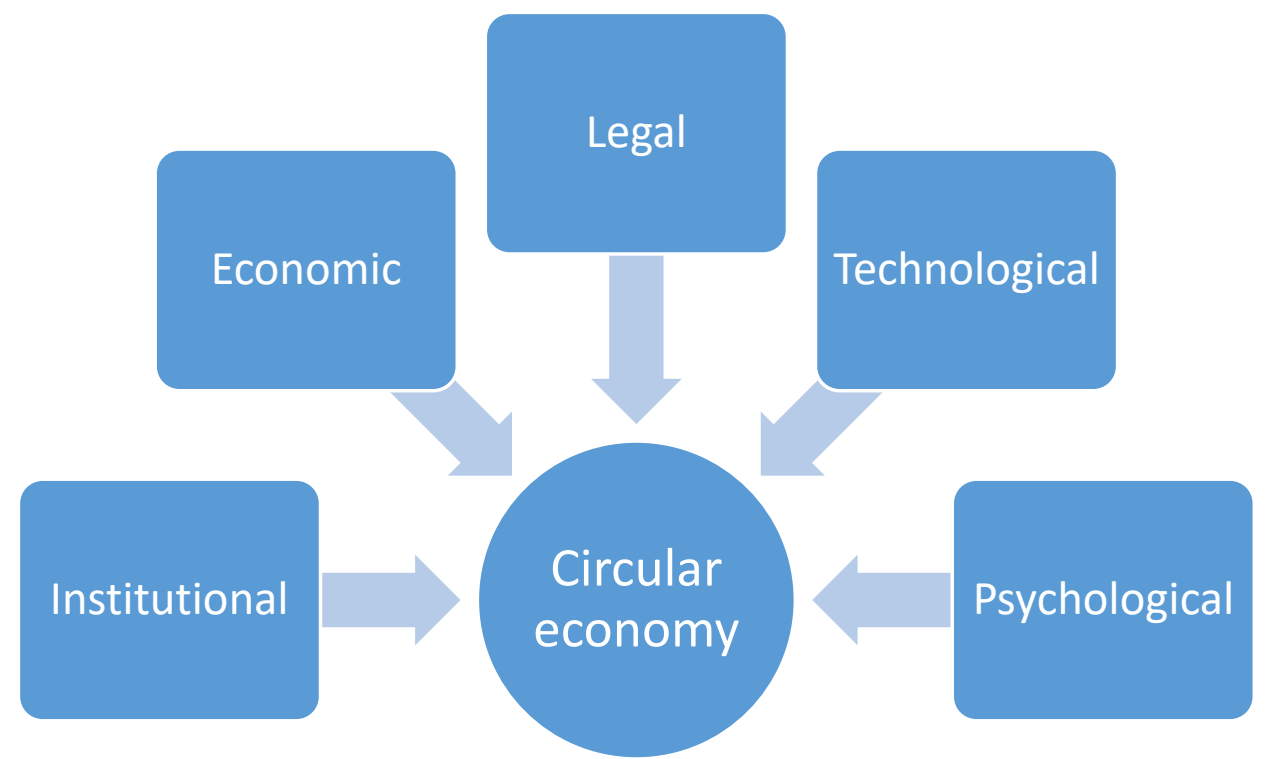

Fig. 1. Barriers to a cyclical economy.

Institutional barriers to the functioning of a cyclical economy are related to the fact that the current economic system is oriented towards the demand of a linear economy. Cyclical entrepreneurship is at a disadvantage. The transition to a cyclical economy leads to an increase in transaction costs, uncertainty, and opportunistic behavior. New cyclical business models (for example, the economy of shared consumption) may be contrary to existing rules, regulations and agreements on working conditions. When calculating GDP, costs for society (external factors) are not taken into account. Therefore, the potential of social design is underestimated. Traditional annual reports and profit and loss statements cover only a part of social expenses $[16,19]$.

Economic barriers cover a wide range of issues. The prices of resources are subject to market fluctuations and sometimes the prices of resources of good quality are uncompetitive. Since social and environmental costs are not reflected in market prices, economic decisions are based on incorrect market signals. Cyclic business models are more difficult to develop, they sometimes require upfront investments, while returns are not defined or distributed over a longer period. Costs and benefits are often unevenly 
distributed across the supply chain. Demand for cyclical offers has not yet been formed. In a growing economy, there may be a shortage of certain professions necessary for a cyclical economy, for example, specialists with technical knowledge or knowledge in the field of information and communication technologies [20].

The traditional development model is based on intensive industrial growth and resourceintensive infrastructure. The physical infrastructure of production, consumption and trade is largely dependent on fossil fuels and is focused on direct production models [21, 22]. For an effective market response, it will be necessary to eliminate subsidies that encourage excessive use of resources and include all "external factors" in the price of resources and energy. However, the experience gained over the course of decades in developing environmental policies has shown that regulations with deep systemic consequences, in particular carbon pricing, can be weakened by special interest groups.

Legal barriers are as follows. Waste management rules prevent the collection and transboundary movement of waste for cyclical use. Higher taxation of labor in laborintensive cyclic activities leads to an increase in costs. Increasing the role of rental relationships can lead to property disputes. Current government policies and legislation are based on the realities of a linear economy. Therefore, they can impede the transition to a cyclical economy, both internationally and nationally.

Technological barriers are associated with the lack of technologies necessary for the processing of company waste, as well as the underdeveloped infrastructure necessary for transporting waste to both the place of its processing and transportation of waste after processing to consumers [23].

Psychological barriers lie in the ignorance of both society as a whole and companies about the circular economy and misunderstanding, as well as underestimation of the benefits that it can provide.

The cyclic model comprehensively affects the economy, the environment and consumption processes. Economic benefits are expressed in reducing the consumption of raw materials and energy resources, increasing the number and changing the structure of jobs. The benefits of companies from introducing circular business models are to increase innovativeness and additional competitive advantages, to create new sources of profit, to increase customer loyalty and to strengthen relationships with partners throughout the value chain. For consumers, the development of a circular economy means the consumption of environmentally friendly products and, in some cases, a decrease in their value. The circular economy also has a significant impact on the environment due to the reduction of $\mathrm{CO} 2$ emissions, the reduction of landfill sites and landfills, and the reduction in the consumption of limited resources. At the same time, the reuse of goods reduces the demand for new ones, which reduces incomes and the number of people employed in the extractive industries. In Figure 2 you can see the positive and negative effects of a cyclical model of the global economy.

Despite the presence of negative effects, the benefits of the development of a cyclical economy are cumulative, therefore many governments are developing special measures to build a closed-loop model [19]. In addition, under certain conditions, barriers to building a cyclical economy can turn into incentives for switching to a cyclical model.

1. Technological progress and transfer of technologies, new methods for designing products and materials, increasing the availability of information about them.

2. Legal instruments, such as toughening and development of environmental legislation and state support in the field of subsidizing companies, waste management, stimulating research projects.

3. Cooperation and integration of companies into global networks of environmentally responsible business will help organize closed supply chains, obtain more accurate 
information about suppliers, reduce potential economic risks, and share costs between all participants in the newly organized closed chain.

4. Reducing the consumption of resources and, accordingly, the demand for them will push the company to diversify its business.

5. Informing society and business about the benefits of a cyclical economy, improving the culture of consumption and a more frugal attitude of people towards nature.

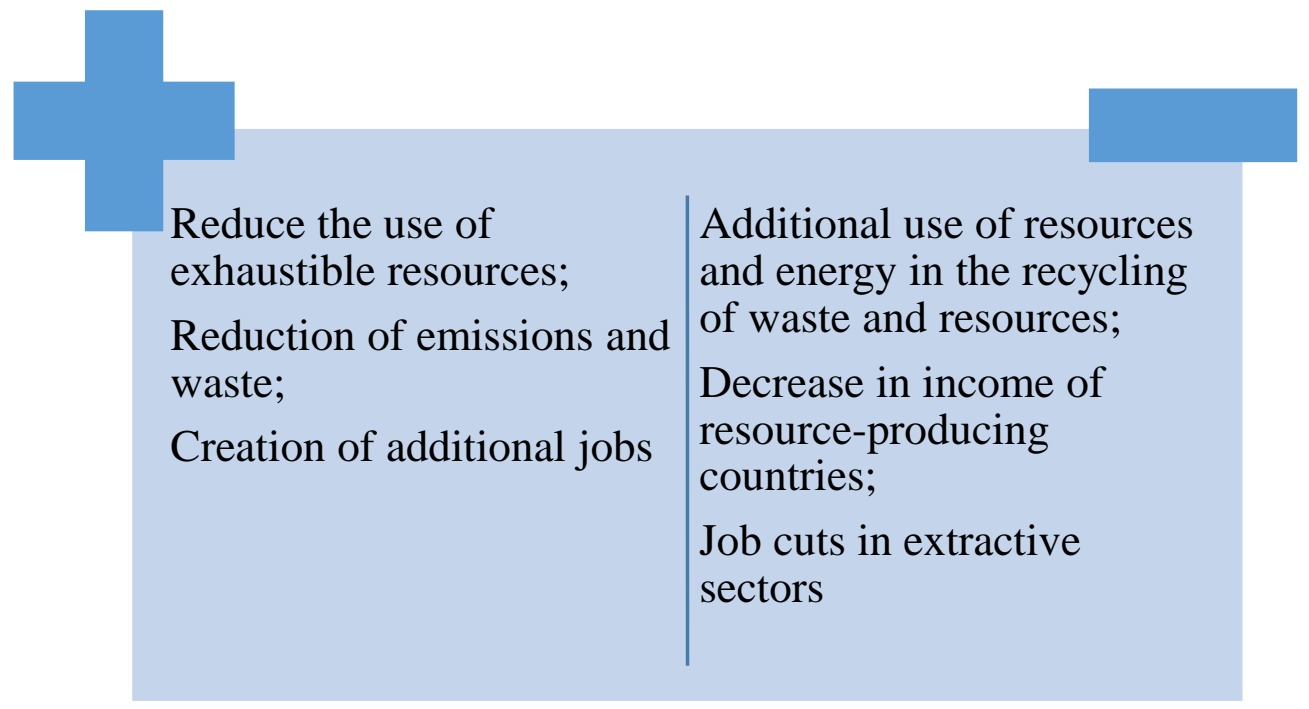

Fig. 2. Positive and negative effects of a cyclical model of the global economy.

When these conditions are realized, it is possible to achieve more closed cycles at enterprises, create more jobs, save a large amount of resources and also improve the ecological state of the global economy and different countries.

\section{Results}

On the basis of the study, the incentives that encourage companies to introduce closed-loop economy models were divided into 5 groups: political, economic, social, technological and environmental. Of great importance are the preparedness of public consciousness, the increasing understanding of entrepreneurs and the population about the harm to health and nature, the use of linear models of production and consumption.

In addition, there are barriers to the introduction of a cyclical economy model. In order to overcome these barriers, state support is needed - financial, informational, regulatory. In addition, it is necessary to increase environmental responsibility.

\section{Discussion}

In developed countries, active efforts are being made to implement the principles of a cyclical economy. These include regulatory measures, as well as economic incentives and financial support for projects focused on the development of a circular economy [24, 25]. The largest companies are introducing circular innovative technologies and closed supply chains.

The development of the circular economy in the Russian Federation will bring a positive environmental effect from the reduction of landfills and landfills, the economic 
effect of increasing energy and resource efficiency, as well as the social effect of the creation of additional jobs as a result of profit for companies in new industries and activities.

\section{Conclusion}

Distinctive features of a cyclical economy are restorative and withdrawn; minimization of consumption of primary raw materials, volumes of final waste disposal; optimization of consumption processes by reusing products. Closed supply chains maximize value over the entire product life cycle with dynamic recovery over relatively long time periods.

The cyclical economy is based on technological, organizational and social innovations, including environmental product design and waste prevention. To improve public welfare, business models are used that are characterized by high end results and low material, energy and environmental costs.

\section{References}

1. C. Kraaijenhagen, C. Van Oppen, N. Bocken, N. Circular Business - Collaborate and Circulate. (Van Hilten, 2016) (1st ed.).

2. Ellen Macarthur Foundation. Intelligent Assets: Unlocking the Circular Economy Potential. Avaliable

at: https://www.ellenmacarthurfoundation.org/assets/downloads/publications/EllenMacArt hurFoundation_Intelligent_Assets_080216.pdf

3. J Vernon Henderson, T. Squires, A. Storeygard, D. Weil, The Global Distribution of Economic Activity: Nature, History, and the Role of Trade. The Quarterly Journal of Economics 133, 357-406 (2018)

4. R. Kube, A. Löschel, H. Mertens, T. Requate, Research trends in environmental and resource economics: Insights from four decades of JEEM. Journal of Environmental Economics and Management 92, 433-464 (2018)

5. J. Kirchherr, D. Reike, M. Hekkert, Conceptualizing the circular economy: An analysis of 114 definitions. Resources, Conservation \& Recycling 127, 221-232 (2017)

6. D. D'Amato, N. Droste, B. Allen, M. Kettunen, K. Lahtinen, J. Korhonen, P. Leskinen, B.D. Matthies, A. Toppinen Green, circular, bio economy: A comparative analysis of sustainability Avenues. Journal of Cleaner Production 168, 716-734 (2017)

7. D. Popp, Environmental Policy and Innovation: A Decade of Research. International Review of Environmental and Resource Economics 13, 265-337 (2019)

8. W. Habla, Climate policy under factor mobility: A (differentiated) case for capital taxation. Journal of Environmental Economics and Management 92, 100-124 (2018)

9. J. Korhonen, A. Honkasalo, J. Seppälä, Circular Economy: The Concept and its Limitations. Ecological Economics 143, 37-46 (2018)

10. Y. Kalmykova, M. Sadagopan, L. Rosado, Circular economy - From review of theories and practices to development of implementation tools. Resources, Conservation and Recycling 135, 190-201 (2018) 
11. D. Reike, W.J.V. Vermeulen, S. Witjes, The circular economy: New or Refurbished as CE 3.0? - Exploring Controversies in the Conceptualization of the Circular Economy through a Focus on History and Resource Value Retention Options. Resources, Conservation and Recycling 135, 246-264 (2018)

12. G. Gaustad, M. Krystofik, M. Bustamante, K. Badami, Circular economy strategies for mitigating critical material supply issues. Resources, Conservation and Recycling 135, 24-33 (2018)

13. T. T.Sousa-Zomer, L. Magalhães, E. Zancul, A. Paulo. Cauchick-Miguel Exploring the challenges for circular business implementation in manufacturing companies: An empirical investigation of a pay-per-use service provider. Resources, Conservation and Recycling 135, 3-13 (2018)

14. S. Ritzén, G. Ölundh Sandström, Barriers to the Circular Economy - Integration of Perspectives and Domains. Procedia CIRP 64, 7-12 (2017)

15. G. Michelini, R. N. Moraes, R- N. Cunha, J. M. H. Costa, Aldo R.Ometto From Linear to Circular Economy: PSS Conducting the Transition. Procedia CIRP 64, 2-6 (2017)

16. N. Millar, E. McLaughlin, T. Börger, The Circular Economy: Swings and Roundabouts? Ecological Economics 158, 11-19 (2019)

17. V. Prieto-Sandoval, C. Jaca, M. Ormazabal, Towards a consensus on the circular economy. Journal of Cleaner Production 179, 605-615 (2018)

18. A. Vorotnikov. The transition to a circular closed-loop economy begins. Avaliable at: http://ecopress.center/page4186642.html

19. Circular Economy: New rules will make EU the global front-runner in waste management and recycling, European Commission - Press release, 2018. Avaliable at: http://europa.eu/rapid/press-release_IP-18-3846_en.htm

20. E. Hille, P. Möbius, Do energy prices affect employment? Decomposed international evidence. Journal of Environmental Economics and Management 96, 1-21 (2019)

21. E. Liu, Industrial Policies in Production Networks. The Quarterly Journal of Economics 134, 1883-1948 (2019)

22. D. A. Keiser, J. S. Shapiro, Consequences of the Clean Water Act and the Demand for Water Quality. The Quarterly Journal of Economics 134, 349-396 (2019)

23. M. Fowlie, M. Greenstone, C. Wolfram, Do Energy Efficiency Investments Deliver? Evidence from the Weatherization Assistance Program. The Quarterly Journal of Economics 133, 1597-1644 (2019)

24. CH. Gollier, Valuation of natural capital under uncertain substitutability. Journal of Environmental Economics and Management 94, 54-66 (2019)

25. R. S. Pindyck, The social cost of carbon revisited. Journal of Environmental Economics and Management 94, 140-160 (2019) 